Caso para Ensino

\title{
Círculo Integrado de Informação: O Desafio de Integração das Polícias Civil e Militar
}

Integrated Information Circle: The Challenge of Integrating the Civil and Military Police

\section{APRESENTAÇÃO}

Em junho de 2015, em virtude das relaçóes interpessoais mantidas com os profissionais de segurança pública, atores da sociedade civil e órgãos públicos, o Dr. Gabriel Ferrando e o Major Felipe Carvalho Barreto foram convidados a participar de uma reuniáo na Subsecretaria de Educação, Valorização e Prevenção (SSEVP) da Secretaria de Estado de Segurança (SESEG) do Rio de Janeiro, com o objetivo de discutir a oportunidade de criação de um curso de análise criminal.

Naquela oportunidade, Dr. Gabriel Ferrando era o delegado titular da 1 ${ }^{\text {a }}$ DP Rocinha e o Major Felipe Carvalho Barreto atuava como superintendente de Inteligência da Coordenadoria de Polícia Pacificadora (CPP), da Polícia Militar do Estado do Rio de Janeiro (PMERJ). Participaram da reunião, além do Dr. Gabriel e do Major Barreto, outros

\footnotetext{
* Autor Correspondente.

1. Fundação Centro Estadual de Estatísticas, Pesquisas e Formação de Servidores Públicos do Rio de Janeiro, Escola de Gestão e Políticas Públicas, Rio de Janeiro, RJ, Brasil.

2. Universidade Federal do Rio de Janeiro, Instituto COPPEAD de Administração, Rio de Janeiro, RJ, Brasil.

Como citar: Mazzurana, L., \& Almeida, V. (2021). Círculo integrado de informação: O desafio de integração das Polícias Civil e Militar. Revista de Administração Contemporânea, 26(2), e200375.
} https://doi.org/10.1590/1982-7849rac2022200375.por representantes da SSEVP, da Subsecretaria de Inteligência (SSINT) da SESEG e o comandante da Unidade de Polícia Pacificadora (UPP) Rocinha, Major Pazini.

Os participantes concluíram que antes de propor um curso de análise criminal, era preciso criar espaços para que delegacia e UPP trocassem informaçôes sobre a dinâmica criminal da área de forma contínua e em tempo para reorientaçáo operacional dos efetivos policiais de ambas as agências. O encontro se encerrou com um encaminhamento: uma reunião seria marcada para apresentar ao secretário de segurança do Rio de Janeiro, Dr. Mariano Beltrame, uma proposta de criação de protocolo para a troca de informaçóes entre as polícias, a ser inicialmente testado pela UPP e DP Rocinha.

Classificaçāo JEL: M1, M14 Editores-chefes: Wesley Mendes-Da-Silva (Fundação Getulio Vargas, EAESP, Brasil) Marcelo de Souza Bispo (Universidade Federal da Paraíba, PPGA, Brasil) Editora Associada: Paula C. P. de S. Chimenti (Universidade Federal do Rio de Janeiro, COPPEAD, Brasil) 당 Pareceristas: Fernando do Amaral Nogueira (Fundação Getulio Vargas, EAESP, Brasil) (1) Adrian Kemmer Cernev (Fundação Getulio Vargas, EAESP, Brasil)

Relatório de Revisão por Pares: O Relatório de Revisão por Pares está disponivel neste link externo. Recebido: 04/12/2020 Última versão recebida em: 09/06/2021 Aceite em: 26/07/202

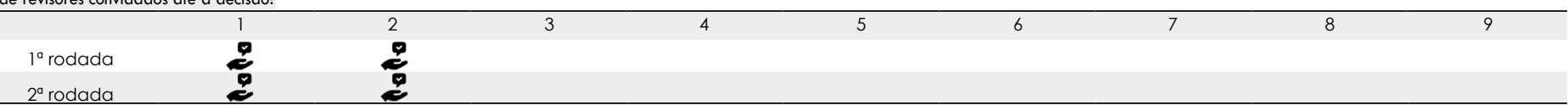


Sugeriu-se, então, a realização de um encontro no mês de outubro, com a participaçáo do secretário de segurança, dos representantes da SSINT, da SSEVP, e da Subsecretaria de Planejamento e Integração Operacional (SSPIO) da SESEG, do coronel coordenador da CPP, da delegada diretora da Academia de Polícia Sylvio Terra (ACADEPOL), do comandante da UPP Rocinha, além do Major Barreto e do Dr. Gabriel, que teriam o desafio de apresentar a proposta, convencer as autoridades do potencial do projeto e obter a autorizaçáo para início.

Todavia, uma preocupação parecia perturbar principalmente os gestores das localidades mais diretamente envolvidas: depois de autorizada, como fazer para tornar a integração, a partir da troca de informaçóes, uma ação institucionalizada, perene e independente da relação interpessoal dos atores locais?

\section{ANTECEDENTES}

O cenário é a favela da Rocinha, localizada entre os bairros da Gávea e de São Conrado, com uma população de 70.491 habitantes. A comunidade foi a $28^{\mathrm{a}}$ no município do Rio de Janeiro a ter implantada uma Unidade de Polícia Pacificadora (UPP), em 29 de setembro de 2012, depois de um processo de ocupação pelas forças de segurança iniciado em 13 de dezembro de $2011^{1}$.

Conforme prevê o texto constitucional em seu artigo 144 (ver Anexo 1), o trabalho de policiamento ostensivo e de preservação da ordem pública era realizado pelos policiais militares lotados na UPP Rocinha, enquanto o de investigação e de polícia judiciária era realizado por policiais civis da $15^{\mathrm{a}} \mathrm{DP}$ - Gávea e de outras unidades de polícia judiciária (UPJ), quando necessário.

Os desafios às forças policiais eram representados pelos números divulgados pelo Instituto de Segurança Pública (ISP), que indicavam aumento significativo de tentativas de homicídio e lesão corporal dolosa a partir do início de $2012^{2}$.

As dificuldades para redução desses indicadores eram potencializadas pela carência de outros serviços públicos, baixa renda e qualidade de moradias, dentre outros itens levados em consideração para atribuir à Rocinha um dos mais baixos índices de desenvolvimento social (IDS) do município do Rio de Janeiro ${ }^{3}$. Somava-se a esse cenário a intensa atuação de grupos criminosos que buscavam estabelecer e/ou consolidar mercados ilegais de proteçáo e tráfico de drogas.

Não bastasse esse contexto adverso para a atuação das forças de segurança, em julho de 2013, o projeto de pacificação se desgastou significativamente em sua legitimidade junto à população. Isso foi motivado quando o morador Amarildo Dias de Souza teve seu paradeiro desconhecido depois de ser visto embarcando em uma viatura da polícia militar. O episódio se deu durante a realização da Operação Paz Armada nos dias 13 e 14 daquele mês. O país foi tomado pela pergunta "Cadê o Amarildo?", que ganhou força durante as manifestaçóes populares de 2013 - amplamente noticiadas pela mídia - e alcançou repercussão mundial. Como resultado dessa ação, a juíza Daniella Alvarez Prado, da 35a Vara Criminal da Capital, condenou 12 dos 25 policiais militares envolvidos no caso pelos crimes de tortura seguida de morte, ocultaçáo de cadáver e fraude processual ${ }^{4}$.

Alguns meses depois, a SESEG e a Polícia Civil do Estado do Rio de Janeiro (PCERJ) anunciaram uma estratégia que visava a apoiar a busca por legitimidade da atuação policial sobre territórios pacificados. Em dezembro de 2013 foram inauguradas duas delegacias para atuação específica na Rocinha ( $\left.11^{\text {a }} \mathrm{DP}\right)$ e no Complexo do Alemão (45 DP).

Essa e outras açóes indicavam que o controle da criminalidade na Rocinha era prioridade para as autoridades de segurança pública e a questáo principal discutida entre os gestores era o estudo de quais estratégias deveriam ser adotadas em curto, médio e longo prazos.

Dentre inúmeras alternativas que foram discutidas e realizadas pelos gestores das instituiçóes de segurança pública, uma foi o "Círculo Integrado de Informaçôes", projeto que aconteceu entre junho de 2015 e dezembro de 2016, envolvendo a Unidade de Polícia Pacificadora da Rocinha (28 UPP - Rocinha) da Polícia Militar do Estado do Rio de Janeiro (PMERJ) e a Delegacia de Polícia da Rocinha (11 a DP - Rocinha) da Polícia Civil do mesmo estado (PCERJ). Esse projeto foi desenvolvido com o objetivo de integrar os dois órgãos policiais a partir da troca de informaçóes.

Os representantes do mais alto nível das instituições policiais e da Secretaria de Estado de Segurança acompanharam o projeto, mas foram os gestores das unidades locais, apoiados por assessores da SESEG, que o moldaram e deram aplicabilidade. Dentre esses agentes, dois tiveram destaque devido ao perfil profissional integrador e inovador: Dr. Gabriel Ferrando - delegado titular da $11^{\text {a }} \mathrm{DP}$ Rocinha - e Major Felipe Carvalho Barreto - que ao longo do processo atuou como superintendente de Inteligência da Coordenadoria de Polícia Pacificadora (CPP).

Esses profissionais identificaram que a reduzida troca de informaçôes entre órgáos policiais que atuam na "ponta da linha" é um dos elementos que dificultam, em diferentes graus, a prestação do serviço policial por ambas as instituições. 


\section{A INTEGRAÇÃO PELA AFINIDADE ENTRE GESTORES}

\section{O oficial da PMERJ}

Partindo da concepçáo de que os fluxos de informações e a qualificação dos dados de inteligência são fundamentais para o processo decisório em qualquer planejamento, foram criados Núcleos de Inteligência em cada UPP, constituídos por um efetivo policial capacitado para colher dados e receber informaçôes relacionadas às dinâmicas criminais e seus fluxos de pessoas e bens na regiáo.

Esses núcleos se ligavam por meio de canais técnicos diretamente com a Divisão de Inteligência da CPP, e essa divisão se articulava com a Coordenadoria de Inteligência da PM (CIPM), que por sua vez interagia com a Subsecretaria de Inteligência da Secretaria de Estado de Segurança (SSINT/SESEG).

Devido à criação dessa divisão de inteligência da CPP, o Major Felipe Carvalho Barreto, na Polícia Militar desde 2001, foi convidado a chefiar essa área em 2015, deixando a função de assessor da Subsecretaria de Planejamento e Integração Operacional (SSPIO) da SESEG que assumiu em 2014 depois do trabalho realizado na UPP Macacos, onde teve sua atuação destacada.

Durante seu período como comandante de UPP, o oficial demonstrou possuir um perfil voltado a integração das forças policiais, que produziu ótimos resultados durante seu tempo de comando na UPP Macacos, como a parceria com a $20^{a}$ DP. A respeito dessa experiência, o oficial comentou: "Foi uma vitória inesquecível. Eu nunca imaginei que com as informaçóes que os policiais militares compartilharam, se pudesse contribuir com uma investigação tão detalhada. Esse trabalho gerou 65 mandados, sendo 12 cumpridos na própria UPP Macacos. O impacto na população foi formidável. A operação foi conjunta entre os policiais da delegacia e da UPP."

Durante o período em que atuou na área de inteligência da CPP, o major conheceu o trabalho realizado por outro gestor na área da Rocinha, Dr. Gabriel Ferrando, titular da $11^{\text {a }} \mathrm{DP}$, em conjunto com o comandante da UPP local. Começavam a se alinhar os elementos que iriam permitir a realizaçáo do projeto-piloto para o Círculo Integrado de Informações.

\section{delegado da PCERJ}

Como forma de aprimorar o trabalho realizado pela Polícia Civil em áreas com UPP, teve início em 2013 um processo que visava a implantar delegacias para a atuação específica sobre territórios pacificados. Assim, o governo do estado inaugurou em 21 de dezembro de 2013 a delegacia de polícia judiciária da Rocinha (11 $\left.{ }^{\text {a }} \mathrm{DP}\right)$, e seu primeiro delegado titular foi o Dr. Gabriel Ferrando.

Vale dizermos que essa delegacia, diferente das demais, teria apenas uma área sob sua circunscrição. Antes a Rocinha tinha suas ocorrências atendidas pela delegacia da Gávea - $15^{\mathrm{a}} \mathrm{DP}$ - e depois da $11^{\mathrm{a}} \mathrm{DP}$, a comunidade passaria a contar com uma unidade de polícia judiciária exclusiva.

O delegado Gabriel Ferrando havia ingressado na Polícia Civil em 2008, e antes de assumir a $11^{\text {a }}$ DP já era reconhecido pelo trabalho realizado em Itaipu, distrito de Niterói, como titular da $81^{\mathrm{a}}$ DP, onde promoveu a integração de esforços com a Polícia Militar, a Polícia Federal e a prefeitura. Esse traço característico voltado para a integração contribuiu para sua indicação a delegado titular para a inauguração da unidade Rocinha.

Em entrevista concedida para a imprensa, já com um mês à frente da delegacia, Dr. Gabriel apontava a importância de se considerar todos os elementos que pudessem robustecer a construçáo dos inquéritos policiais: "É preciso uma açáo de inteligência. Estamos catalogando informaçóes e analisando-as. A Rocinha está hoje num processo de pacificaçáo, e existem focos de resistência. Vamos entender por que existem, onde estão, quem são as pessoas. E a partir daí vamos capturá-las. Isso requer tempo, porque os mandados de prisão e os inquéritos devem ter um acervo probatório consistente, para que esses elementos não sejam presos e absolvidos em seguida" .

Para o levantamento dessas informaçóes, Dr. Gabriel buscava a aproximação com o comando da UPP Rocinha, primeiro com a Major Priscilla de Oliveira Azevedo, e, depois, com o Major Sidnei Pazini, que a substituiu.

De acordo com Dr. Gabriel, essa proximidade permitiu que tanto o gestor da $11^{\text {a }}$ DP quanto o da UPP Rocinha reconhecessem que o número de confrontos entre policiais militares e criminosos aumentava na medida em que permaneciam baixos, ou até se reduziam, os números de cumprimentos de mandados de prisão. Um esforço pessoal entre os dois gestores para facilitar a troca de informaçóes entre seus policiais foi feito, e constantemente era incentivada a parceria entre os agentes operadores.

\section{A OPORTUNIDADE}

A solicitação feita pela SSPIO para um curso de análise criminal que pudesse ser realizado de forma integrada pelas polícias, que foi direcionada para a Subsecretaria de Educação, Prevenção e Valorização da Secretaria de Estado de Segurança (SSEVP/SESEG), acabou sendo a oportunidade para uma iniciativa maior. 
Assim, foi desenvolvida na SSEVP uma agenda para alinhamento preliminar de como seria a capacitaçáo solicitada, contando com a presença de integrantes da CPP, SSEVP, SSPIO e SSINTE. Na ocasião, o Major Barreto, representando a CPP, mencionou o trabalho que acompanhava e era desenvolvido pelo Dr. Gabriel na Rocinha em parceria com a UPP, como possível ponto de partida para a pretendida capacitação por tratar de abordagens integradas com a UPP e também voltadas para analisar a situação criminal na Rocinha.

A proposição foi aceita e, em novo encontro na SSEVP semanas depois, com os mesmos participantes da última reunião, mas agora com a presença da diretora da ACADEPOL, Dr. ${ }^{a}$ Jéssica Oliveira de Almeida, Dr. Gabriel apresentou o que vinha implementando na área da Rocinha, em parceria com o comandante da UPP, através de quatro tópicos.

O primeiro explicitou a parceria entre os gestores da $11^{\text {a }}$ DP e da UPP que buscava fazer com que policiais civis e militares trocassem mais informaçóes, quaisquer que fossem, de forma contínua e com a maior qualidade possível, mantendo preservados os fluxos institucionais de cada agência, mas dando maior celeridade na circulaçáo dessas informaçóes entre os operadores de cada unidade.

Em seguida foi trazida a ideia geral do Círculo Integrado de Informaçôes, que era criar condiçôes para que os policiais militares recebessem da delegacia informações sobre mandados a serem cumpridos, movimentaçóes dos criminosos, áreas com maiores registros de ocorrências em delegacia, orientaçóes sobre a melhor maneira de preservar as evidências, além de contato direto com os investigadores e delegado. Ao mesmo tempo, os policiais civis passariam a conhecer as dinâmicas da comunidade através da maior capilaridade da Polícia Militar no terreno, recebendo relatos e demais elementos que pudessem, em conjunto, robustecer inquéritos.

Logo após foi indicado um dos resultados esperados que seria, em tese, um aumento no número de mandados de prisão, ao mesmo tempo que uma redução de confrontos armados aleatórios, posto que um número maior de operaçóes planejadas reduziria esse risco. As informaçóes sobre prisóes seriam compartilhadas pelo delegado com os policiais militares que auxiliaram na coleta de informaçóes, e o criminoso seria preso por mais tempo, posto que não seria encaminhado por força de uma prisão em flagrante, em geral mais precária, reduzindo o risco de os policiais militares voltarem a confrontar o mesmo criminoso.

$\mathrm{O}$ quarto tópico mencionou que o projeto poderia ser mensurado por um acompanhamento dos números de confrontos armados entre forças de segurança e criminosos, e pela quantidade de mandados de prisão expedidos e cumpridos na área.

O grupo que assistia à apresentação aprovou a proposta. Major Barreto e Dr. Gabriel aceitaram o desafio de realizar a apresentação em conjunto para as autoridades. A reunião aconteceu semanas depois com a presença do secretário de segurança, Dr. Mariano Beltrame, o coordenador de polícia pacificadora, Cel. Laviano, a fim de obter dessa autoridade o aval para o início da execução do projeto de forma institucional na UPP Rocinha, uma vez que em relação à Polícia Civil já havia essa autorização, e com a participação do comandante da UPP Major Pazini. $\mathrm{Na}$ ocasião, foi apresentado o conceito geral do Círculo Integrado da Informação: "A imersão no terreno da PM, propiciado pela ocupação permanente no ambiente, viabiliza a percepçáo de inúmeros elementos de informação. A orientada captação desses informes e o seu compartilhamento atuarão na revelaçáo de integrantes da criminalidade acobertados pelo anonimato, além de propiciarem uma melhor compreensão da nova dinâmica criminosa. As constataçôes alcançadas com essa troca de informaçóes, aliadas ao compartilhamento dos mandados de prisão pela DP com os que auxiliaram no levantamento das informaçóes, contribuirão com a redução da lesividade da atuaçáo policial e um aumento de sua produtividade e eficiência posto pelo aumento de operaçóes integradas e planejadas para prisão por meio de mandados judiciais, reduzindo-se as prisôes por flagrante de delito, que em geral expóem mais o policial militar e a comunidade."

$\mathrm{Na}$ oportunidade, Dr. Gabriel apresentou um mapeamento elaborado pela $11^{\text {a }} \mathrm{DP}$ - Rocinha, que indicava o alto número de confrontos, em sua maioria com a mesma dinâmica: "policiais militares quando em patrulhamento avistaram - ou foram avistados por - marginais que realizaram disparos contra a guarnição".

A apresentação buscou sensibilizar as autoridades de que quanto maior for a troca de informaçóes, em tese, maior será a possibilidade de operaçóes planejadas e, assim, menor o número de confrontos durante patrulhamentos de rotina. Ao mesmo tempo, maior será a probabilidade de concessão de mandados de prisão a partir de inquéritos mais bem instruídos por causa das informaçóes compartilhadas entre as agências, com o cumprimento conjunto desses mandados de prisão pelos policiais civis e militares envolvidos na coleta de informaçôes.

O projeto foi aprovado pelas autoridades e teve o início marcado com a realização de um workshop na ACADEPOL (ver, no Anexo 2, a Resolução Conjunta do secretário de Estado de Segurança e do secretário de Comunicação Social, que descentraliza a execução de créditos orçamentários para realização da oficina "Círculo de informações integrado: um processo de integração da PCERJ e PMERJ"), com a presença do secretário de Segurança e outras autoridades. 
Durante um dia, 47 policiais militares e 10 inspetores da Polícia Civil, todos lotados na Rocinha, ouviram seus gestores e trocaram contatos. $\mathrm{O}$ acesso e o fluxo de informaçóes foram estabelecidos entre os gestores e pactuados com o restante do efetivo.

Segundo a fala dos palestrantes Major Barreto e Dr. Gabriel, a partir desses ajustes, buscava-se evitar ao máximo os confrontos aleatórios e não planejados - diminuindo, assim, a vitimização de moradores e de policiais -, bem como aumentar e robustecer o número de mandados de prisão. Com isso, esperava-se reduzir as prisóes em flagrante e aumentar as decorrentes de ordens judiciais em que as prisóes seriam realizadas em conjunto pela Polícia Civil e pela Polícia Militar, que contribuiriam com as informaçóes para a expediçáo do mandado.

O Major Barreto esclareceu como percebia a integração entre as agências a partir da troca de informaçóes: "Informação como está sendo colocado nesse projeto e Inteligência são coisas complementares. Não é entrar na área de Inteligência, onde existem graus de sigilo no que é processado. Digo que o objetivo não é concorrer com Inteligência de Segurança Pública, que entendo ser um outro tipo de atividade, mas focar no que é coletado na ponta e que pode ser fonte tanto para a Inteligência quanto para a delegacia e a unidade policial militar planejarem suas açóes, como no próprio Policiamento Orientado para a Solução de Problemas (POP). O que importa é como a informação é coletada pelo agente na ponta, e como ela é processada. Essas informaçóes podem servir a todos, podem alimentar os canais técnicos de inteligência, o comandante da UPP e o titular da delegacia, sem que precisem ser excludentes, e essa troca pode contribuir para a melhoria dos resultados de todos. Observamos que a delegacia tem uma informação mais quantitativa a partir dos Registros de Ocorrências (RO), e a unidade policial militar tem uma informação mais qualitativa por conta da capilaridade e da presença diuturna do policiamento na comunidade. Uma informaçáo complementa a outra e podem gerar melhores resultados se compartilhadas em tempo adequado."

Em complemento, Dr. Gabriel explicitou: “Temos que buscar projetos que fomentem a integração, com uma discussão séria, técnica, sem demagogia e sem vaidades. Com cada instituição trabalhando dentro da sua expertise, oferecendo o que cada uma tem de melhor".

\section{OS PRIMEIROS RESULTADOS}

Com essas premissas em mente, os primeiros resultados começaram a aparecer na área da Rocinha. A exemplo do que ocorreu à época do Major Barreto à frente da UPP Macacos em parceria com a 20a DP, um inquérito foi aberto pelo Dr. Gabriel e robustecido por informaçóes da Polícia Militar. A partir de uma operação em conjunto, foi possível identificar inúmeros criminosos, tirando-os do anonimato com vídeos e demais elementos probatórios. Isso gerou um trabalho tão bem articulado que o Ministério Público elogiou a técnica utilizada e a forma de trabalho, sugerindo-a como possível protocolo a ser utilizado pelas instituiçóes.

Como exemplo mais objetivo da troca de informações idealizada pelo projeto, e dos resultados que poderiam gerar, Dr. Gabriel relatou em 11 de dezembro de 2015 uma ocorrência da $11^{\text {a }}$ DP (Rocinha) em particular: "Agentes policiais da Unidade, no dia de hoje, obtiveram sucesso em apreender [o nome do indivíduo foi omitido], em decorrência do cumprimento de mandado de busca e apreensão pelo crime de tentativa de homicídio e associação para o tráfico. O referido nacional foi capturado no hospital Miguel Couto quando da descoberta de que o mesmo encontrava-se internado no local em razão de ferimentos por projétil de arma de fogo (PAF). O mesmo é descrito como partícipe de inúmeros confrontos na comunidade da Rocinha, exercendo a função de 'soldado do tráfico'. A descoberta de seu paradeiro foi auxiliada, também, com a troca de informaçóes com policiais da UPP Rocinha que receberam informes e fotos do nacional internado no hospital e repassaram para a Unidade. Parabéns aos policiais envolvidos, com destaque para o soldado Fernandes da UPP Rocinha, que repassou as informaçóes para a unidade, sendo a primeira cana do Círculo Integrado da Informação, projeto-piloto encampado pela $11^{\text {a }} \mathrm{DP}$ - Rocinha e UPP da Rocinha, com apoio do CPP."

\section{A FALTA DE FÔLEGO}

Novas reunióes de trabalho com a participação dos gestores de ambas as polícias e SESEG eram necessárias, mas, apesar do início promissor, não ocorreram. Sucederam-se mudanças de gestores na Secretaria e Polícias Civil e Militar e nenhum outro workshop foi realizado.

Dr. Gabriel comentou: "na prática tivemos resistência, por falta de divulgação, envolvimento de outros gestores, ficou muito na mão de quem estava no projeto, e com as mudanças de comando, o projeto perdeu fôlego". Por sua vez, Major Barreto ponderou que "não houve muitos resultados porque ocorrerem mudanças, eu saí da CPP e fui para outra missão, o Dr. Gabriel também saiu, o projeto acabou não seguindo. Percebi que o trabalho fica muito na iniciativa particular. A dificuldade é trazer institucionalidade".

Major Barreto foi transferido de sua função na CPP para o Estado Maior Geral da PMERJ, afastando-se do projeto em 2016 e, em novembro do mesmo ano, Dr. Gabriel assumiu outra titularidade na 12a DP (Copacabana). 
Entre junho de 2015 e dezembro de 2016, o Círculo Integrado de Informação constituiu-se das seguintes açóes: articulação entre os protagonistas do caso e autoridades; publicação de uma resolução (Anexo 2); realização de um workshop para capacitação; encontros entre policiais da delegacia e da UPP da regiāo da Rocinha de modo aleatório, que facilitavam a prisão de infratores; e, como resultado principal, conclusão de um inquérito policial que se valeu das informaçōes do Círculo Integrado para gerar a prisão de diversos criminosos. Apesar dessa trajetória do projeto, e dos primeiros resultados alcançados, o Círculo Integrado de Informação não se consolidou como ação de promoção de integração.

Poucos anos depois, a Secretaria de Estado de Segurança foi extinta, em $1^{\circ}$ de janeiro de 2019, sob o argumento de que a pasta não promovia de modo efetivo a integração entre as polícias. Em lugar da SESEG, as Polícias Civil e Militar foram tornadas Secretarias de Estado, nos termos do decreto n. ${ }^{\circ} 46.544$.

À época da realização do projeto - e em entrevistas recentes -, Dr. Gabriel, Major Barreto e outros envolvidos na ação compartilharam as mesmas preocupações: considerando o ambiente organizacional e cultural das polícias, como fazer com que a parceria para a troca de informaçóes seja institucional e não dependa de relaçóes pessoais entre os gestores? $\mathrm{Ou}$, como diz o jargáo popular, como essa troca de informaçóes pode acontecer sem que seja equivocadamente percebida como "colocar a azeitona na empada do outro"? Essas são reflexóes que parecem ainda interpelar os profissionais das forças policiais.

\section{NOTAS}

1. http://www.ispdados.rj.gov.br/UPP.html, recuperado em 25 de abril, 2018

2. http://www.ispdados.rj.gov.br/UPP.html, recuperado em 25 de abril, 2018

3. https:/www.data.rio/documents/fa85ddc76a524380ad7fo60e3006ee97/ about recuperado em 26 de abril, 2018.

4. G1 Rio (2016, December 01). Caso Amarildo: Juíza condena 12 dos 25 policiais militares acusados. G1. Retrieved from http://g1.globo.com/rio-de-janeiro/noticia/2016/02/casoamarildo-juiza-condena-13-dos-25-policiais-militaresacusados.html

5. Otoni, A. C. (2014, February 05). Novo delegado da Rocinha aposta na integração com a comunidade. $\mathrm{O}$ Globo. Retrieved from https://oglobo.globo.com/rio/ bairros/novo-delegado-da-rocinha-aposta-na-integracaocom-comunidade-11503802\#ixzz5GiFh8Axw 


\section{ANEXO 1}

\section{Art. 144 da Constituição da República Federativa do Brasil de 1988}

Art. 144. A segurança pública, dever do Estado, direito e responsabilidade de todos, é exercida para a preservação da ordem pública e da incolumidade das pessoas e do patrimônio, através dos seguintes órgãos:

I - polícia federal;

II - polícia rodoviária federal;

III - polícia ferroviária federal;

IV - polícias civis;

$\mathrm{V}$ - polícias militares e corpos de bombeiros militares.

VI - polícias penais federal, estaduais e distrital.

$\$ 1^{\circ}$ A polícia federal, instituída por lei como órgão permanente, organizado e mantido pela União e estruturado em carreira, destina-se a:

$[\ldots]$

$\$ 2^{\circ}$ A polícia rodoviária federal, órgão permanente, organizado e mantido pela União e estruturado em carreira, destinase, na forma da lei, ao patrulhamento ostensivo das rodovias federais.

$§ 3^{\circ}$ A polícia ferroviária federal, órgão permanente, organizado e mantido pela Uniáo e estruturado em carreira, destinase, na forma da lei, ao patrulhamento ostensivo das ferrovias federais.

$\$ 4^{\circ}$ Às polícias civis, dirigidas por delegados de polícia de carreira, incumbem, ressalvada a competência da União, as funções de polícia judiciária e a apuração de infrações penais, exceto as militares.

$\S 5^{\circ}$ Às polícias militares cabem a polícia ostensiva e a preservação da ordem pública; aos corpos de bombeiros militares, além das atribuiçóes definidas em lei, incumbe a execução de atividades de defesa civil.

$\$ 5^{\circ}$-A. Às polícias penais, vinculadas ao órgão administrador do sistema penal da unidade federativa a que pertencem, cabe a segurança dos estabelecimentos penais.

$\$ 6^{\circ}$ As polícias militares e os corpos de bombeiros militares, forças auxiliares e reserva do Exército subordinam-se, juntamente com as polícias civis e as polícias penais estaduais e distrital, aos Governadores dos Estados, do Distrito Federal e dos Territórios.

$\$ 70$ A lei disciplinará a organização e o funcionamento dos órgãos responsáveis pela segurança pública, de maneira a garantir a eficiência de suas atividades.

$\$ 8^{\circ}$ Os Municípios poderão constituir guardas municipais destinadas à proteção de seus bens, serviços e instalaçóes, conforme dispuser a lei.

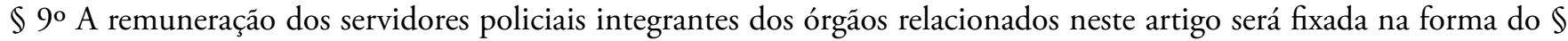
40 do art. 39.

$\$ 10$. A segurança viária, exercida para a preservação da ordem pública e da incolumidade das pessoas e do seu patrimônio nas vias públicas:

$[\ldots]$ 


\section{ANEXO 2}

\section{Secretaria de Estado de Segurança ATO DO SECRETÁRIO E DO SUBSECRETÁRIO RESOLUÇÁO CONJUNTA SESEG/SSCS N. 191 DE 30 DE NOVEMBRO DE 2015}

Descentraliza a execução de créditos orçamentários na forma que especifica.

\section{O SECRETÁRIO DE ESTADO DE SEGURANÇA E O SUBSECRETÁRIO DE COMUNICAÇÃO SOCIAL} DA CASA CIVIL, no uso de suas atribuiçốes legais [...], e tendo em vista o que consta do Processo Administrativo n. ${ }^{\circ}$ E-09/009/79/2015,

\section{RESOLVEM:}

Art. $1^{\circ}$ - Descentralizar a execução do crédito orçamentário, na forma a seguir especificada:

I - OBJETO - Realização do Workshop - Círculo integrado de informação: um processo de integração PCERJ e PMERJ. $[\ldots]$

Art. $2^{\circ}$ - Esta Resolução Conjunta entra em vigor na data de sua publicação, revogadas as disposiçôes em contrário.

Rio de Janeiro, 30 de novembro de 2015.

\section{JOSÉ MARIANO BENINCÁ BELTRAME}

Secretário de Estado de Segurança

\section{CARLOS ALBERTO YOUNG TOLOMEI DE ARAÚJO}

Subsecretário de Comunicação Social

Fonte: Resolução conjunta SESEG/SSCS n. ${ }^{\circ} 191$ de 30 de novembro de 2015 (2015). Diário Oficial do Estado do Rio de Janeiro. Retrieved from https://www.jusbrasil.com.br/diarios/106236893/doerj-poder-executivo-14-12-2015-pg-7 


\section{ANEXO 3}

\section{GLOSSÁRIO}

ACADEPOL: Academia de Polícia Sylvio Terra da Polícia Civil

CIPM: Coordenadoria de Inteligência da Polícia Militar do Estado do Rio de Janeiro

CPP: Coordenadoria de Polícia Pacificadora da Polícia Militar do Estado do Rio de Janeiro

DP: Delegacia de Polícia Civil

IDS: Índice de Desenvolvimento Social

ISP: Instituto de Segurança Pública

PAF: Projétil de arma de fogo

PCERJ: Polícia Civil do Estado do Rio de Janeiro

PMERJ: Polícia Militar do Estado do Rio de Janeiro

POP: Policiamento Orientado para Problema

RO: Registro de Ocorrência em Delegacia de Polícia Civil

SESEG: Secretaria de Estado de Segurança do Rio de Janeiro

SSEVP: Subsecretaria de Educação, Valorização e Prevenção da Secretaria de Estado de Segurança do Rio de Janeiro

SSINT: Subsecretaria de Inteligência da Secretaria de Estado de Segurança do Rio de Janeiro

SSPIO: Subsecretaria de Planejamento e Integração Operacional da Secretaria de Estado de Segurança do Rio de Janeiro

UPP: Unidade de Polícia Pacificadora 


\section{RESUMO}

Contexto: o caso narra a criação do Círculo Integrado de Informação, projeto-piloto que ocorreu em uma área circunscrita à comunidade da Rocinha, capitaneada por gestores das Polícias Civil e Militar, que foi executado por meio de parceria entre a $11^{\text {a }} \mathrm{DP}$ - Rocinha e a $28^{\mathrm{a}} \mathrm{UPP}$ - Rocinha. Essa ação buscava desenvolver protocolos para a troca de informaçóes de modo contínuo, efetivo e, sobretudo, institucionalizado entre as agências policiais locais. Entretanto, apesar de bons resultados alcançados, a iniciativa não se consolidou. Metodologia: as informaçóes foram coletadas a partir de dados secundários e entrevistas dos gestores que participaram do processo - Dr. Gabriel Ferrando, titular da $11^{\text {a }}$ DP, e Major Felipe Carvalho Barreto, então superintendente de Inteligência da Coordenadoria de Polícia Pacificadora (CPP). Objetivos: discutir como as Polícias Civil e Militar se organizam e atuam. Resultados: desenvolvimento de análises sobre aspectos relacionados à organização e cultura das instituições policiais em relação ao tema integração. Conclusáo: o caso permite compreender limites e potencialidades da integração entre as polícias, tendo por base a discussáo sobre as possíveis razôes de o Círculo Integrado de Informações ter sido descontinuado.

Palavras-chave: inteligência; institucionalização; integração; Polícia Civil; Polícia Militar.

\section{OBJETIVOS EDUCACIONAIS}

Este caso foi desenvolvido para estimular a discussão sobre o papel constitucional da Polícia Militar e Polícia Civil em relação aos limites e potencialidades de atuação integrada entre essas agências nos níveis operacionais e estratégicos.

Espera-se, ao final da discussão do caso, que os discentes possam alcançar os seguintes objetivos de aprendizagem: (a) identificar limites e potencialidades para institucionalização de práticas que promovam mudanças nos processos organizacionais das polícias; (b) discutir sobre como a cultura, organização e atribuição constitucional de cada agência contribuem para resistências à troca de informaçôes entre as unidades operacionais; (c) propor dinâmicas que possam contribuir com o aprimoramento da troca de informaçóes entre as polícias nos níveis operacionais e estratégicos, incluindo contribuiçóes das comunidades onde atuam.

\section{ABSTRACT}

Context: the case narrates the creation of the Integrated Information Circle, a pilot project that took place in an area limited to the Rocinha community, led by managers of the civil and military police, which was carried out through a partnership between the 11th DP - Rocinha and the 28th UPP - Rocinha. This action sought to develop protocols for the exchange of information in a continuous, effective, and, above all, institutionalized manner between local police agencies. However, despite the good results achieved, the initiative has not been consolidated. Methodology: the information was collected from secondary data and interviews from the managers who participated in the process - Dr. Gabriel Ferrando, chief of the 11th DP, and Major Felipe Carvalho Barreto, then intelligence superintendent of the Pacifying Police Coordination (CPP). Objectives: To discuss how the civil and military police organize and act. Results: development of analyzes on aspects related to the organization and culture of police institutions about the theme of integration. Conclusion: the case allows us to understand the limits and potential of integration between the police, based on the discussion about the possible reasons why the Integrated Information Circle has been discontinued.

Keywords: intelligence; institutionalization; integration; civil police; military police.

\section{FONTES DE INFORMAÇÕES}

As informações utilizadas foram coletadas a partir de fontes primárias e secundárias. Entre as fontes primárias foram ouvidos dois gestores diretamente envolvidos à época com a experiência apresentada no caso: o delegado titular da $11^{\text {a }}$ DP - Rocinha, Dr. Gabriel Ferrando, e o superintendente de Inteligência da Coordenadoria de Polícia Pacificadora, Major PM Felipe Carvalho Barreto. As fontes secundárias foram relatórios técnicos, matérias de jornais e sítios eletrônicos.

\section{DISCIPLINAS E PÚBLICO-ALVO}

Este caso foi desenvolvido para discutir como as Polícias Civil e Militar se organizam e atuam, evidenciando dificuldades para institucionalizar práticas que promovam 
mudanças nas organizações, e prestando-se para utilização em disciplinas relacionadas à Organização e Cultura das Polícias, Planejamento Estratégico e Processo Decisório em cursos de graduação ou pós-graduação em Administração Pública. Também é recomendado para as disciplinas voltadas para estudos em inteligência, gestão e liderança em ambientes inseridos no sistema de segurança pública e justiça criminal.

\section{PLANO DE ENSINO}

Este caso para ensino é um instrumento didático que foi desenhado para possibilitar a aprendizagem por meio de processo indutivo. Caso os discentes não sejam familiarizados com o ambiente institucional das Polícias Civil e Militar, recomenda-se a leitura prévia dos seguintes materiais: "Capítulo VII - Desafios e aprendizados da política de pacificação" da obra Unidade de Polícia Pacificadora - UPP: da origem do programa à politica de pacificação (Secretaria de Estado de Segurança do Rio de Janeiro - SESEG [SESEG], 2015); páginas 94 a 101 do artigo "A integração da Polícia Militar e Polícia Civil do estado do Amazonas com o advento do plano de revitalização da segurança pública" (Mathias, 2012); e páginas 168 a 174 do artigo "Segurança cidadã: formas de envolvimento e propensão do cidadão à coproduçấo de segurança pública no Distrito Federal" (Martins, Farias, \& Angelo, 2019). Também espera-se que os alunos em geral conheçam alguns aspectos da teoria institucional, e para isso indicamos a leitura das páginas 64 a 71 do artigo "Uma introdução à teoria institucional do ponto de vista sociológico" (Chaerki, Ribeiro, \& Ferreira, 2019).

Sugere-se fortemente a utilização dos três estágios de aprendizagem preconizados pelo método do caso: preparação individual prévia; discussão em pequenos grupos; e discussão plenária.

A preparação individual prévia implica a distribuição antecipada do caso para os discentes, juntodos textosindicados para leitura. Sugere-se que o caso seja disponibilizado com pelo menos uma semana de antecedência.

O caso pode ser trabalhado em aulas de 80 (ou 120) minutos. O docente deve estabelecer um plano de distribuição de tempo, considerando a distribuição típica de horários de aula da instituição de ensino superior.

A abertura da discussão em plenário (Lâminas 1 e 2 - Apêndice) pode exigir 15 (ou 20) minutos. Em seguida, o docente pode reservar um período de 30 (ou 40) minutos para que os discentes discutam o caso em pequenos grupos antes da discussáo plenária. A discussão das questóes do caso (Lâminas 3 a 5 - Apêndice) pode consumir 30 (ou 50) minutos. Recomenda-se reservar os cinco (ou dez) minutos restantes para o encerramento da discussão plenária.

\section{ABERTURA DA DISCUSSÃO DO CASO EM PLENÁRIO}

A abertura da discussão pode ser usada para que os discentes discutam as atribuiçôes e missóes institucionais das agências policiais para além do que está previsto de forma concisa no texto constitucional, em seu artigo 144 (Constituição da República Federativa do Brasil, 1988):

"Art. 144. A segurança pública, dever do Estado, direito e responsabilidade de todos, é exercida para a preservação da ordem pública e da incolumidade das pessoas e do patrimônio, através dos seguintes órgãos: ... IV - polícias civis; $\mathrm{V}$ - polícias militares e corpos de bombeiros militares. ..."

“ $\$ 4^{\circ}$ Às polícias civis, dirigidas por delegados de polícia de carreira, incumbem, ressalvada a competência da Uniāo, as funçóes de polícia judiciária e a apuração de infrações penais, exceto as militares. [Grifos nossos].

$\$ 5^{\circ}$ Às polícias militares cabem a polícia ostensiva e a preservação da ordem pública; aos corpos de bombeiros militares, além das atribuições definidas em lei, incumbe a execução de atividades de defesa civil. [Grifos nossos].

$\$ 6^{\circ}$ As polícias militares e os corpos de bombeiros militares, forças auxiliares e reserva do Exército subordinam-se, juntamente com as polícias civis e as polícias penais estaduais e distrital, aos Governadores dos Estados, do Distrito Federal e dos Territórios.

$\$ 7^{\circ}$ A lei disciplinará a organização e o funcionamento dos órgãos responsáveis pela segurança pública, de maneira a garantir a eficiência de suas atividades."

Para estimular a discussão na abertura da sessão, sugerimos as seguintes questôes: (a) Quais elementos de informação podem ser fornecidos pelo policiamento ostensivo - atividade desenvolvida pelos policiais militares fardados - que auxiliem na condução ou abertura de um inquérito policial? As respostas tendem a vir de discentes mais familiarizados com a Polícia Civil. Em seguida, o docente pode propor a seguinte questão: (b) Quais são os elementos de informação que podem ser fornecidos pela delegacia da área para auxiliar o trabalho do policiamento ostensivo? $\mathrm{O}$ docente pode usar as Lâminas 1 e 2 simultaneamente para registrar as contribuiçóes dos discentes. Em grupos náo familiarizados com o trabalho policial, sugere-se acrescentar a questáo: (c) Quais elementos de informação podem ser fornecidos pela comunidade que possam auxiliar o policiamento ostensivo e as atividades de investigação? Nesse 
caso as respostas tendem a partir das reflexôes produzidas a partir da leitura do artigo sobre coprodução da segurança pública, e da experiência de cada um em eventuais interaçóes com policiais.

\section{QUESTÕES PARA DISCUSSÃO}

A seguir, apresentamos um conjunto de questôes (discussion questions) que podem ser usadas para suportar a análise do caso durante a etapa de discussão em plenário:

1. Quais são as principais dificuldades para institucionalizar práticas que promovam a troca de elementos de informaçáo entre a Polícia Civil e a Polícia Militar em nível operacional, e não apenas entre canais de inteligência e/ou de alta cúpula?

2. É necessária alguma alteração da organização policial, seja da Polícia Civil, seja da Polícia Militar, para que ocorra essa institucionalização?

3. É necessária alguma alteração na cultura das polícias para que essa troca de informaçóes efetivamente ocorra?

\section{ANÁLISE DO CASO}

Ao longo da narrativa do caso, é possível notar a dificuldade do Dr. Gabriel e do Major Barreto na criação de espaços para trocas de informaçóes entre os operadores da delegacia e da UPP. Eles buscam essa interaçáo primeiro de maneira pessoalizada, depois com o apoio da Secretaria de Segurança, mas ainda assim o projeto tem dificuldade de se manter, e de fato perde fôlego com o tempo, apesar dos bons resultados alcançados.

A questão fundamental que está presente, e será foco da discussão do caso, é se essa troca de informaçóes é dificultada pela forma de organização das polícias, uma voltada apenas para investigação e outra apenas para a ostensividade e prevenção, ou mesmo da cultura das polícias em que alguns de seus integrantes já se reconhecem como pertencentes a instituiçóes separadas, ou se apesar dessa organização determinada pelo texto constitucional é possível, desejável e viável a integração no âmbito da operação, para buscar reflexos imediatos no atendimento ao cidadáo. Esse contexto também permite analisar o quanto os indivíduos podem influenciar mudanças institucionais, e, sobretudo, torná-las perenes em suas organizaçóes.

Nesse sentido, a 'teoria institucional' oferece repertório teórico relevante para analisar a capacidade dos protagonistas em influenciar suas instituiçóes, bem como compreender suas limitaçóes em tornar a experiência do Círculo Integrado de Informações uma prática institucionalizada e contínua.
A teoria institucional é voltada para o estudo do comportamento das organizaçóes, e "ganhou proeminência como uma explicação popular e poderosa para a ação individual e organizacional" (Dacin, Goodstein, \& Scott, 2002, p. 45).

Para Chaerki, Ribeiro e Ferreira (2019), essa teoria nos auxilia a perceber a importância dos aspectos relacionais do ambiente organizacional, entre eles os normativos e culturais, e não apenas focar em elementos materiais, como a disputa por recursos. Essa abordagem ilumina tanto a relevância da articulação entre as dimensões simbólica e prática quanto o papel dos atores individuais que eventualmente influenciam a criação e a manutenção dos sistemas institucionais.

O caso em estudo apresenta a experiência de gestores que buscam influenciar a maneira como as suas instituiçóes interagem, considerando o sistema de regras em que se inserem. A teoria institucional problematiza esse contexto, e pode ser usada em articulação com o caso para analisar situaçóes assemelhadas que ocorram em organizações diversas, bem como na compreensão sobre as suas potencialidades e limitaçôes.

Uma das consideraçôes possíveis reside na questão de que qualquer instituição é dinâmica, e incorpora mudanças que ocorrem tanto por meio de pequenos movimentos promovidos por atores isolados ou grupos quanto através de rupturas mais drásticas. Identificar como a capacidade de agência do indivíduo se expressa e intervém nesses processos é importante para analisar o potencial de mudança dessas iniciativas e sua institucionalização. Nessa abordagem também é relevante saber náo apenas se o agente possui a intenção de realizar algo novo, mas se possui o poder para isso.

Nesse sentido, é possível verificar que a mudança institucional, de acordo com Dacin, Goodstein e Scott (2002), pode ocorrer:

"desde os níveis mais microinterpessoais e suborganizacionais até os níveis mais macro-sociais e globais. Pode ocorrer em períodos relativamente breves e concentrados ou ao longo do tempo medido em décadas ou séculos. E pode ocorrer de forma incremental, de modo que observadores e participantes dificilmente percebam qualquer mudança, ou abruptamente, em episódios dramáticos que apresentam grandes descontinuidades com os padróes anteriores" (Dacin, Goodstein, \& Scott, 2002, p. 48).

O caso revela pontos de discussão interessantes sobre o quanto de poder os protagonistas possuem para implementar suas ideias, assim como apresenta alguns desdobramentos inesperados, como a materialização de um inquérito policial elaborado com base nas informaçóes produzidas pelo Círculo 
Integrado de Informaçôes estabelecido entre os policiais da UPP Rocinha e DP Rocinha, que gerou prisões em número maior que esperado, e que não seriam possíveis sem essa experiência de integraçáo institucional.

Conforme Chaerki et al. (2019), o resultado não intencional é outro ponto da teoria institucional que auxilia na interpretação da perenidade ou da descontinuidade de iniciativas. Reside no entendimento de que para além do que o agente buscou implementar, existem consequências não premeditadas da sua ação, que ocorrem independentemente de sua vontade e intenção.

Os autores também indicam que precisamos observar com atenção a dimensão simbólica, uma vez que uma instituiçáo pode ser considerada como um sistema social perene e dinâmico, resultado da interaçáo social e composto por padróes, modelos de expectativas, e elementos simbólicos aceitos como legítimos em determinado ambiente, tempo e espaço (Chaerki et al., 2019).

Essa abordagem contribui com a análise do caso, pois por essa perspectiva o trabalho da polícia náo se resume ao previsto no texto constitucional, mas abrange todo um conjunto de expectativas sociais sobre a atuação das Polícias Civil e Militar. Quanto maior for o entendimento de que as atividades das polícias, ou de qualquer outro tipo de instituiçáo, estão em sintonia com um sistema socialmente construído de crenças, valores e normas, maior será a legitimidade dessas organizações.

Ocorre que existe uma discussão sobre a atuação das polícias e seu alinhamento com as expectativas da sociedade. Para Cano (2006), existe uma herança autoritária que considera a polícia como:

"um órgão de proteção do Estado e das elites que o dirigiam, contra os cidadáos que representavam um perigo para o status quo, as chamadas "classes perigosas". A transição do modelo de uma polícia de controle do cidadão para uma polícia de proteção das pessoas é gradual e ainda não foi concluída. Ademais disso, o Estado brasileiro conserva resquícios de sua formação oligárquica, como a prisão especial para as pessoas com formação universitária ..." (Cano, 2006, p. 141).

Além disso, as polícias estaduais formaram-se separando as atividades de policiamento ostensivo, que pertence à Polícia Militar, e de investigaçáo, própria da Polícia Civil. Essa divisão forçou alguns estados a estabelecer, segundo Cano (2006), "tentativas de integrar a atuação das Polícias Militar e Civil ... tomaram medidas para integrar na prática o trabalho das duas corporaçóes. O estado do Pará, por exemplo, criou uma academia conjunta para as duas polícias, sem, no entanto, unificálas, de forma que a convivência entre elas pudesse desde o princípio da formação ajudar a superar desconfianças e divergências. Outros estados, como Minas Gerais e Rio de Janeiro, instituíram áreas de segurança conjunta para as duas polícias, obrigando, dessa forma, que as jurisdições geográficas das duas instituiçóes - batalhóes da Polícia Militar e delegacias da Polícia Civil - coincidissem, pela primeira vez, na tentativa de promover um trabalho conjunto. Até o momento o grau de acerto dessa iniciativa é bastante modesto" (Cano, 2006, p. 144).

Essa integração buscaria aproximar a Polícia Militar, que realiza o policiamento nas ruas, da Policia Civil, que encaminha os procedimentos cartorários e de investigação dos casos trazidos pela PM e das demais denúncias levadas diretamente pela comunidade. Contudo, existem resistências a essa atuação complementar, que de acordo com Mathias (2012) podem ser assim resumidas:

"Há várias argumentaçōes contrárias à efetividade da integração entre as polícias militares e civis, a saber: a improdutividade na divisão da responsabilidade entre duas gestôes policiais; duas polícias com diferentes padrôes de comportamento profissional, diferentes estruturas hierárquicas e submetidas a diferentes normas atuando numa mesma área; duplo aparato, que por sua vez demanda dispêndios excessivos com investimentos e custeios; duplicação de efetivos, instalações, equipamentos, estruturas administrativas e operacionais; unificação de legislação; compatibilização de estruturas organizacionais; código disciplinar comum; equiparação hierárquica e de salários; centros integrados de operação; áreas comuns de treinamento, entre outros aspectos" (Mathias, 2012, p. 101).

O caso em estudo revela uma tentativa de superar essas resistências, e seus protagonistas poderiam ser associados à noção de empreendedores institucionais, definidos como aqueles "atores com interesse em arranjos institucionais específicos e que mobilizam recursos para criar novas instituiçôes ou transformar as existentes" (Chaerki et al., 2019, p. 74). 
Questão 1: Como tornar institucional a troca de elementos de informação entre a Polícia Civil e a Polícia Militar em nível operacional, e não apenas entre canais de inteligência e/ou de alta cúpula?

Recomenda-se que o docente estimule os discentes a discutirem a institucionalização da troca de informaçóes entre as agências em âmbito de operação a partir da seguinte questão de transição:

QT1 - Quais canais podem ser usados para que essas informações - apontar para o registro da contribuição dos discentes nas Lâminas 1 e 2 - sejam trocadas com a velocidade necessária e sem dependerem de relaçôes pessoais entre os gestores?

O docente deve considerar que embora exista em muitas situaçóes, como no presente caso, um bom entrosamento entre os gestores, isto é, uma boa relação pessoal entre os comandantes e delegados, a relação da ponta e dos escalóes inferiores pode estar distante do entrosamento esperado. A consequência disso é uma inadequada troca de informaçóes, o que pode repercutir diretamente no combate à criminalidade local.

A fluidez e o dinamismo na troca de elementos de informação são considerados primordiais para a melhor 'compreensão' da atuação da traficância local (exemplo: nova atuação da criminalidade que passa a não mais ser encontrada com quantidades de drogas que caracterizem traficância), a 'identificaçáo’ de criminosos (exemplo: retirada do anonimato de integrantes do tráfico) e a 'elaboração de estratégias' na repressão à criminalidade (exemplo: investimento em uma eficiente atuação integrada e não apenas por meio de patrulhamento de rotina com eventuais confrontos armados quando do encontro de criminosos em flagrante de delito).

A integração entre as agências faz gerar um ambiente propício para o surgimento de novos canais para troca de informações. Entre esses canais, podemos ter: a criação de instrumentos de coleta; a formatação de documentos que sistematizem as informaçôes colhidas diuturnamente; momentos de trocas entre agentes com relatos mais detalhados; retorno da delegacia dos mandados de prisão expedidos e de criminosos que atuam na região. Sem essas formas de sistematização, as informações podem ser perdidas ou ficarem desconexas.

Nesse ponto da discussão pode ser problematizada a dificuldade para promover mudanças em organizaçóes, trazendo a teoria institucional como repertório teórico que contribua para analisar as potencialidades e limitaçóes que os protagonistas possuíam para institucionalizar a experiência que propunham. Essa abordagem pode ser estendida para análise de processos de institucionalizaçáo de mudanças em várias formas de organização, não apenas as policiais.

\section{Questão 2 - É necessária alguma alteração da organização policial, seja da Polícia Civil, seja da Polícia Militar, para que ocorra essa institucionalização?}

Recomenda-se que o docente estimule os discentes a discutirem se a forma constitucional de organização das polícias estaduais influencia a troca de informaçôes entre as agências em nível de operação a partir da seguinte questão de transição:

QT2 - Considerando as sugestóes apontadas registradas na Lâmina 3 -, existem indicaçóes que demandem alteração na organização de alguma das polícias? Quais?

Diferentes contextos históricos, políticos e sociais promoveram distintas conformaçóes de forças de segurança em todo o mundo. Um dos sistemas mais peculiares em termos de organização das polícias é o brasileiro. Isso porque, no Brasil, as polícias com os maiores efetivos são as estaduais e, de modo diverso do que ocorre na maior parte das agências de segurança no mundo, nenhuma delas é capaz de promover prevenção e repressão de forma completa (Bayley, 2002).

Articular essas duas finalidades em uma mesma polícia equivale a dizer que esta agência é uma instituição que realiza o ciclo completo, que "executa todas as fases da atividade policial: prevençáo, repressão, investigação e apuração dos crimes" (Silva, 2003, p. 417). Não é o caso da Polícia Civil e da Polícia Militar no contexto brasileiro.

Diz-se, então, que a segurança pública brasileira tem nos estados um modelo dicotômico de polícia, não por existir mais de uma polícia, o que ocorre em praticamente todos os países, mas porque cada uma das duas instituiçóes policiais vai até certo ponto do trabalho (Lima, 1989).

Rolim (2007) classifica o modelo brasileiro como bipartido:

Esta estrutura de policiamento, em cujo centro há uma 'bipartição', produziu a realidade peculiar da existência de duas polícias nos estados que devem fazer, cada uma, a metade do "ciclo de policiamento". Dito de outra forma, cada polícia estadual é, conceitualmente, uma polícia pela metade porque ou investiga ou realiza as tarefas de policiamento ostensivo. Uma delas efetua prisóes, a outra colhe provas; uma patrulha, a outra recebe as denúncias etc." (Rolim, 2007, p. 12). 
Também, de forma atípica, não há no Brasil uma polícia local, mas, sim, guardas municipais - também chamadas de guardas civis - que mesmo cada vez mais se aproximando formal e substantivamente de polícias locais, ainda não são assim consideradas pelo texto constitucional. Mesmo que venham a ser reconhecidas oficialmente como polícias locais, também não serão agências que realizarão o ciclo completo de polícia. Apenas a Polícia Federal e Rodoviária Federal têm esse papel, entretanto, com efetivos bem menores e com um país continental como circunscrição (ver Art. 144 no Anexo 1).

Nesse ponto pode ser trazida a dificuldade em promover mudanças de caráter evolutivo em ambientes normativamente rígidos. Pode-se discutir o quanto o processo de institucionalização de práticas que buscam redefinir parâmetros da organizaçáo tende a sofrer resistências sem que tenha o mérito de seu conteúdo avaliado quanto ao potencial de aprimoramento institucional.

\section{Questão 3 - É necessária alguma alteração na cultura das polícias para que essa troca de informações ocorra?}

Recomenda-se que o docente estimule os discentes a discutir se a cultura das duas polícias bicentenárias potencializa a troca de informaçóes entre as agências ou é uma barreira, a partir da seguinte questão de transição:

QT3 - Tendo em vista as observaçóes feitas sobre alteraçôes organizacionais - registradas na Lâmina 4 -, é necessário fomentar mudanças na cultura das polícias para viabilizar essa troca de informaçóes? Quais?

As instituições policiais brasileiras nasceram separadas, reproduzindo o modelo ibérico, e assim permaneceram, criando identidades distintas (Holloway, 1997). A Polícia Militar permaneceu com seu papel preventivo e ainda hoje atua como força auxiliar do Exército. E a Polícia Civil se construiu pautada num modelo burocrático inquisitorial (Lima, 1995).

Com essas premissas, o dia a dia do trabalho policial de cada uma dessas agências foi configurando formas de agir muito específicas entre os membros dessas instituiçóes. E a chamada cultura policial ou ethos policial, que se diferencia conforme seja o agente policial civil ou militar (Poncioni, 2014).

Como as polícias estaduais têm essa separação institucional muito bem demarcada, a cultura policial também opera dessa maneira. Em outras palavras, a Polícia Militar e a Polícia Civil possuem tradiçóes e aspectos culturais distintos. Isso pode eventualmente contribuir para açóes isoladas e concorrentes, em lugar de planejamentos complementares e cooperativos. Assim, o desafio maior reside no desenvolvimento de estratégias que permitam a parceria entre essas instituiçóes, e que possam integrar suas atividades justamente porque cada qual não realiza o ciclo completo de polícia. É isso que torna fundamental a troca de informaçóes e cooperação entre elas, como um dos pressupostos para a produtividade mais efetiva em relação aos serviços que prestam à sociedade.

Esse ponto da discussão permite ainda observar que o ambiente cultural muitas vezes não é considerado na compreensão sobre como a organização é percebida pela sociedade. $\mathrm{O}$ caso permite analisar a relaçáo das expectativas sociais com a resistência que propostas de mudança sofrem para serem institucionalizadas.

\section{ENCERRAMENTO DA DISCUSSÃO DO CASO}

É válido ressaltar que um caso para ensino não possui respostas certas ou erradas. Trata-se aqui da discussão primeira sobre o reconhecimento da importância na troca de informaçóes ao nível das unidades que estão prestando diretamente o serviço à população. Em segundo lugar vem a discussão sobre quais seriam as formas para viabilizar essa troca de informaçôes e reconhecer eventuais barreiras, sejam organizacionais, sejam culturais.

A partir dessa discussão, pode-se pensar em formas de atuação efetivamente integrada, que respeitem a organização e a cultura das polícias, e contribuam para a troca de informaçôes entre as instituiçôes não apenas em nível estratégico, mas principalmente em nível operacional entre as unidades de ambas as polícias.

$\mathrm{O}$ estudo desses elementos permite acionar a teoria institucional como referencial teórico, que contribui para a análise dos processos de mudança nas organizaçóes, e o quanto os indivíduos são capazes de influenciar práticas que venham a se tornar perenes e que aprimorem o serviço prestado.

\section{USO ALTERNATIVO DO CASO}

Embora o caso tenha sido originalmente elaborado para ser utilizado na perspectiva CBL (case-based learning), se o docente assim o preferir, o caso também poderá ser usado na perspectiva de PBL (problem-based learning). Para que tal seja possível, sugere-se a utilização da técnica pedagógica de RPG (role-playing game), mediante a organização dos discentes em duplas, sendo que um dos discentes deverá assumir o papel de oficial superior da PMERJ e o outro o papel de delegado da PCERJ. 
Para dar início à dinâmica, o docente poderia formular a seguinte proposta de trabalho para os discentes:

Em recente reuniáo da cúpula da segurança pública o Círculo Integrado de Informaçóes realizado na área da Rocinha entre 2015 e 2016 foi apresentado como 'boa práticá, e os tomadores de decisão optaram por retomar o projeto. Um oficial superior da PMERJ e um delegado da PCERJ serão designados para apresentar um planejamento conjunto atualizado a partir daquela experiência. A primeira providência dessa equipe será sugerir elementos

\section{REFERÊNCIAS}

Bayley, D. H. (2002). Padróes de policiamento (2. Ed.). São Paulo: EDUSP.

Cano, I. (2006). Políticas de segurança pública no Brasil: Tentativas de modernizaçáo e democratizaçáo versus a guerra contra o crime. Revista Internacional de Direitos Humanos, 3(5), 136-155. https://doi.org/10.1590/S1806-64452006000200007

Chaerki, K. F., Ribeiro, G., \& Ferreira, J. M. (2019). Uma introdução à teoria institucional do ponto de vista sociológico. Caderno de Administração, 27(1), 62-91. https://doi.org/10.4025/cadadm.v27i1.48409

Constituição da República Federativa do Brasil de 1988. (1988). Constituição da República Federativa do Brasil de 1988. Brasília: Câmara dos Deputados. Retrieved from http:// www.planalto.gov.br/ccivil 03/constituicao/constituicao. $\underline{\mathrm{htm}}$

Dacin, M. T., Goodstein, J., \& Scott, W. R. (2002). Institutional theory and institutional change: Introduction to the special research forum. Academy of Management Journal, 45(1), 43-46. https://doi.org/10.5465/amj.2002.6283388

Holloway, T. H. (1997). Polícia na cidade do Rio de Janeiro: Repressáo e resistência numa cidade do século XIX. Rio de Janeiro: Editora FGV.

Lima, R. K. (1989). Cultura jurídica e práticas policiais: A tradição inquisitorial no Brasil. Revista Brasileira de Ciências Sociais, 4(10), 65-84. Retrieved from https://app.uff.br/riuff/handle/1/9052 de informação que o policiamento local possa oferecer para auxiliar na construção do inquérito policial e, ainda, indicar elementos que a delegacia de polícia da área possa compartilhar a fim de auxiliar o desenvolvimento do policiamento ostensivo.

Outra possibilidade, caso o professor assim o desejar, será optar por recortar o caso atual, reservando a seção 'A falta de fôlego' para ser entregue aos alunos durante a discussão plenária para encaminhar a discussão de encerramento do caso.

Lima, R. K. (1995). A polícia da cidade do Rio de Janeiro: Seus dilemas e paradoxos. Rio de Janeiro: Forense.

Martins, I. M., Farias, J. S., \& Angelo, L. A., Junior. (2019). Segurança cidadã: Formas de envolvimento e propensão do cidadão à coprodução de segurança pública no Distrito Federal. Contextus - Revista Contemporânea de Economia e Gestão, 17(2), 160-189. https://doi.org/10.19094/contextus.v17i2.41013

Mathias, N. R. (2012). A integração da polícia militar e polícia civil do estado do Amazonas com o advento do plano de revitalização da segurança pública. Revista Cientifica de Pesquisa em Segurança Pública da Polícia Militar de Mato Grosso (PMMT), 8, 96-120. http://revistacientifica. pm.mt.gov.br/ojs/index.php/semanal/article/view/183/0

Poncioni, P. (2014). Identidade profissional policial. In R. S. de Lima, J. L. Ratton, \& R. G. de Azevedo (Orgs.), Crime, polícia e justiça no Brasil. São Paulo: Editora Contexto.

Rolim, M. (2007). Análises e propostas: A segurança como um desafio moderno aos direitos humanos. São Paulo: Fundação Friedrich-Ebert.

Secretaria de Estado de Segurança do Rio de Janeiro. (2015). Unidade de Polícia Pacificadora - UPP: Da origem do programa à politica de pacificaçâo. Rio de Janeiro: SESEG. Retrieved from https://www.academia.edu/39198993/ Unidade de Polícia Pacificadora UPP da origem do programa à política de pacificaçáa

Silva, J. (2003). Segurança pública e polícia: Criminologia crítica aplicada. Rio de Janeiro: Editora Forense. 


\section{Autoria}

\section{Leonardo Mazzurana*}

Fundação Centro Estadual de Estatísticas, Pesquisas e Formação de Servidores Públicos do Rio de Janeiro, Escola de Gestão e Políticas Públicas

Av. Carlos Peixoto, n. 54, Botafogo, 22290-090, Rio de Janeiro, RJ, Brasil

E-mail: leonardomzv@gmail.com

(D) https://orcid.org/0000-0003-3012-1463

\section{Victor Almeida}

Universidade Federal do Rio de Janeiro, Instituto COPPEAD de Administração

Rua Pascoal Lemme, n. 355, Cidade Universitária, 21941-918, Rio de Janeiro, RJ, Brasil

E-mail: valmeida@coppead.ufrj.br

(D) https://orcid.org/0000-0002-4433-0787

* Autor Correspondente

\section{Financiamento}

Os autores relataram que não houve suporte financeiro para pesquisa deste artigo.

\section{Conflito de Interesses}

Os autores informaram que não há conflito de interesses.

\section{Direitos Autorais}

A RAC detém os direitos autorais deste conteúdo.

\section{Contribuições dos Autores}

$1^{\circ}$ autor: conceituação (liderança); investigação (liderança); administraçáo de projeto (suporte); escrita - rascunho original (igual); escrita - revisão e edição (igual).

$2^{\mathbf{o}}$ autor: metodologia (liderança); administração de projeto (liderança); escrita - rascunho original (igual); escrita revisão e ediçãoo (igual).

\section{Verificação de Plágio}

A RAC mantém a prática de submeter todos os documentos aprovados para publicação à verificação de plágio, mediante o emprego de ferramentas específicas, e.g.: iThenticate.

\section{Método de Revisão por Pares}

Este conteúdo foi avaliado utilizando o processo de revisão por pares duplo-cego (double-blind peer-review). A divulgação das informaçôes dos pareceristas constantes na primeira página é feita somente após a conclusão do processo avaliativo, e com o consentimento voluntário dos respectivos pareceristas.

\section{Disponibilidade dos Dados}

A RAC incentiva o compartilhamento de dados mas, por observância a ditames éticos, não demanda a divulgaçáo de qualquer meio de identificaçáo de sujeitos de pesquisa, preservando a privacidade dos sujeitos de pesquisa. A prática de open data é viabilizar a reproducibilidade de resultados, e assegurar a irrestrita transparência dos resultados da pesquisa publicada, sem que seja demandada a identidade de sujeitos de pesquisa. 


\section{APÊNDICE A}

\begin{tabular}{|c|c|c|c|c|}
\hline Lâmina 1 & Lâmina 2 & Lâmina 3 & Lâmina 4 & Lâmina 5 \\
\hline $\begin{array}{l}\text { Como o policiamento pode } \\
\text { contribuir com o inquérito } \\
\text { policial? }\end{array}$ & $\begin{array}{l}\text { Como a delegacia de polícia } \\
\text { pode contribuir com o } \\
\text { policiamento? }\end{array}$ & $\begin{array}{l}\text { Quais canais podem ser } \\
\text { usados para viabilizar a troca } \\
\text { de informaçóes? }\end{array}$ & $\begin{array}{l}\text { Para construir os canais é } \\
\text { preciso alguma alteração na } \\
\text { organização das polícias? }\end{array}$ & $\begin{array}{l}\text { Para consolidar os canais é } \\
\text { preciso alguma alteração na } \\
\text { cultura das polícias? }\end{array}$ \\
\hline $\begin{array}{l}\text { - Relatos } \\
\text { - Informaçóes sobre } \\
\text { confrontos } \\
\text { - Abordagens } \\
\text { - ... }\end{array}$ & $\begin{array}{l}\text { - Informações sobre } \\
\text { mandatos de prisóes } \\
\text { - Mapeamento de áreas } \\
\text { com grande número de } \\
\text { ocorrências de confrontos } \\
\text { - Fotos de procurados } \\
\text { - } . .\end{array}$ & $\begin{array}{l}\text { - Protocolos comuns de } \\
\text { atuação } \\
\text { - Reuniôes periódicas entre } \\
\text { as equipes } \\
\text { - Relatórios conjuntos } \\
\text { - Articulaçáo com a } \\
\text { comunidade local } \\
\text { - ... }\end{array}$ & $\begin{array}{l}\text { - Maior descentralização } \\
\text { - Mudança na disseminação } \\
\text { da informaçáo } \\
\text { - Mudança na gestão da } \\
\text { informação } \\
\text { - Institucionalização de } \\
\text { boas práticas } \\
\text { - Apoio a iniciativas de } \\
\text { inovaçáo } \\
\text { - ... }\end{array}$ & $\begin{array}{l}\text { - Alterar visão de } \\
\text { competiçáo/concorrência } \\
\text { - Integraçáo como valor } \\
\text { - Cidadão como foco } \\
\text { - Reconhecer a expectativa } \\
\text { social sobre o trabalho } \\
\text { policial } \\
\text { - ... }\end{array}$ \\
\hline
\end{tabular}

Figura A1. Quadro proposto. 